\title{
Inferior Long-Term Outcome of Renal Transplantation in Patients with Diabetes mellitus
}

\author{
M.R. Narayanan Nampoory ${ }^{a}$ Kaivilayil V. Johny ${ }^{b}$ Jamal N. Costandia \\ Ram K. Gupta ${ }^{a}$ Madhavan P. Nair ${ }^{a}$ Mohmoud Samhan ${ }^{c}$ \\ Ibrahim A. Al-Muzairaia Mustafa Al-Mousawic \\ Department of Medicine, a Mubarak Al-Kabeer Hospital, bFaculty of Medicine, and \\ 'Hamad Al-Essa Organ Transplant Center, Kuwait
}

\section{Key Words}

Diabetes mellitus · Kidney transplantation, complications, outcome

\begin{abstract}
Objective: To retrospectively review the long-term outcome of renal transplant in diabetics at Mubarak AlKabeer Hospital and Hamad Al-Essa Organ Transplant Center, Kuwait from 1983 to 1998. Methods: There were 631 renal transplant patients, comprising 79 (12.5\%) patients with pretransplant diabetes mellitus (pre-TDM), $117(18.5 \%)$ patients with post-transplant diabetes mellitus and 435 (69\%) nondiabetics (ND). Subjects with posttransplant diabetes mellitus were excluded from the comparative analysis. Distribution of sex, source of donors and mode of immunosuppression were similar in pre-TDM and ND groups. Results: Fifty-three (67\%) recipients in pre-TDM and $90(20.5 \%)$ in the ND group ( $p<$ 0.01 ) were above 45 years of age. However, 26 (33.3\%) pre-TDM and 345 (79.5\%) ND were below age 45 . Among those who died, coronary artery disease led to death in $36 \%$ of pre-TDM and $27 \%$ in ND. Hyperlipidemia requiring drug therapy was observed in $37 \%$ pre-TDM and $6 \%$ ND. The incidence of severe infections was nearly twice
\end{abstract}

\section{KARGER}

Fax + 41613061234

E-Mail karger@karger.ch

www.karger.com

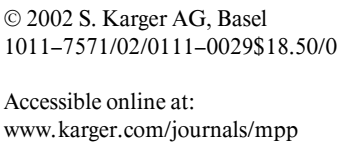

in pre-TDM over ND recipients (1.9 vs. 1.0 per patient, $\mathrm{p}<$ 0.001). Acute rejection episodes were more frequently seen in pre-TDM (43\%) than ND (33\%), however the difference was not statistically significant. The patient survivals at 1,5, 10, 14 years were significantly lower in preTDM $(84,65,58$ and 58\%, respectively) than in ND (97, 93,86 and $82 \%$, respectively). The major contributory factors were severe infections and coronary artery disease. The cumulative graft survival showed a similar pattern (52\% in pre-TDM, $73 \%$ in ND at 10 years). However, when death is excluded, the 10-year pure graft survival probability was similar for the pre-TDM and ND groups (76\% vs. $80 \%$ ). Conclusion: Our study indicates poor patient survival in pre-TDM due to coronary artery disease and infections, whereas the pure long-term graft survival was equally good in pre-TDM and ND transplant recipients.

Copyright $\odot 2002$ S. Karger AG, Basel

\section{Introduction}

Diabetics represent the largest single category of new patients receiving end-stage disease care in many countries [1]. In contrast to the 1970 s when chronic diabetics 
were rarely accepted for any form of renal replacement therapy, they are now regularly accepted for all types of renal replacement therapy. The survival rate of uremic diabetic patients treated with chronic hemodialysis was extremely poor compared to those who had kidney transplantation and nondiabetic dialysis patients [2-5]. However, with improvements in hemodialysis, transplantation and advent of chronic ambulatory peritoneal dialysis, 1-year survival of uremic diabetics has increased to $70 \%$ [6]. This improvement in patient survival has spurred transplant centers to accept more diabetics for renal transplantation.

Outcome of renal transplantation in patients with pretransplant diabetes mellitus (pre-TDM) compared to that of nondiabetics (ND) is still debated. Because of the significant morbidity and mortality clinicians doubted the success of transplantation in uremic diabetics [7]. Some centers have reported higher mortality and lesser patient and graft survivals in diabetics compared to ND $[7,8]$. However, other authors have found similar patient and graft survival in both these groups [7-12]. This prompted us to review our experience with transplantation in uremic diabetics and compare it with that in ND.

\section{Subjects and Methods}

During the period from 1983 until 1998, 631 renal transplant recipients were followed up in the Nephrology Unit of Mubarak AlKabeer Hospital and Hamad Al-Essa Organ Transplant Center in Kuwait. These patients received 640 grafts and included 79 (12.5\%) patients with pre-TDM, $117(18.5 \%)$ with post-transplant diabetes mellitus (PTDM) and 435 (69\%) ND. The pre-TDM group included 32 with type 1 and 47 with type 2 diabetes mellitus. Subjects with PTDM were excluded from the present study to avoid influence of results by effect of PTDM. In addition to information on age, sex, donor type, immunosuppressive therapy, dialysis, primary renal disease, details of rejection episodes and infections, graft and patient outcome were also collected by retrospective review of hospital records. In this study data on the pre-TDM group was then compared with that in ND recipients. Acute rejection is defined as an immediate deterioration of allograft function that is associated with specific pathologic changes in the renal allograft. While chronic rejection is slowly progressive allograft dysfunction, which occurs after the 1st year of transplantation, associated with proteinuria and variable histological renal allograft changes involving blood vessels, glomeruli, interstitium and tubules.

\section{Immunosuppressive Therapy and Prophylaxis}

Most renal transplant recipients were on triple-drug immunosuppression with prednisolone $(1 \mathrm{mg} / \mathrm{kg}$ tapered to $10 \mathrm{mg} /$ day in 6 months), cyclosporin A (7 mg/kg/day tapered to $1-2 \mathrm{mg} / \mathrm{kg} /$ day in 6 months) and azathioprine (1-1.5 mg/kg tapered to $1 \mathrm{mg} / \mathrm{kg} /$ day in 6 months). Monoclonal anti-T-cell antibody (OKT3) and antilymphocyte globulin were not used in the induction protocol. Intrave-
Table 1. Demographic features of subjects with pre-TDM and of ND

\begin{tabular}{|c|c|c|c|c|}
\hline & \multicolumn{2}{|c|}{ Pre-TDM } & \multicolumn{2}{|l|}{ ND } \\
\hline & $\mathrm{n}$ & $\%$ & $\mathrm{n}$ & $\%$ \\
\hline \multicolumn{5}{|l|}{ Sex } \\
\hline Male & 47 & 59.5 & 287 & 66 \\
\hline Female & 32 & 40.5 & 148 & 34 \\
\hline \multicolumn{5}{|l|}{ Age, years } \\
\hline$<30$ & 6 & 8 & 147 & 33.8 \\
\hline $31-45$ & 20 & 25.3 & 198 & 45.5 \\
\hline $46-60$ & 39 & 49.4 & 76 & 17.5 \\
\hline$>61$ & 14 & 17.3 & 14 & 3.2 \\
\hline \multicolumn{5}{|l|}{ Nationality } \\
\hline Kuwaiti & 62 & 78.5 & 235 & 54 \\
\hline Non-Kuwaiti Arabs & 15 & 19 & 147 & 33.8 \\
\hline Others & 2 & 2.5 & 52 & 12.2 \\
\hline \multicolumn{5}{|l|}{ Primary renal disease } \\
\hline Diabetic nephropathy & 52 & 65.8 & - & - \\
\hline Chronic glomerulonephritis & 7 & 8.9 & 157 & 36.1 \\
\hline Chronic tubulointerstitial disease & 13 & 16.5 & 163 & 37.5 \\
\hline Hereditary renal disease & 3 & 3.8 & 20 & 4.6 \\
\hline Hypertensive nephrosclerosis & 1 & 1.2 & 11 & 2.5 \\
\hline Others & 3 & 3.8 & 84 & 19.3 \\
\hline
\end{tabular}

nous methylprednisolone pulses and/or OKT3 were used in the treatment of rejection epidoses. All patients had prophylactic oral nystatin, trimethoprim-sulfamethoxazole and acyclovir regularly for the first 6 months after transplantation.

\section{Statistics}

Fisher's exact test was used to compare differences in groups for significance. Survivals were done using life table and log rank statistics was used for determining differences between two actual survival rates. Differences were considered significant if $\mathrm{p}$ value was $<0.05$.

\section{Results}

Demographic features of patients in pre-TDM and ND groups are shown in table 1 . While $79 \%$ of ND were below the age of 45 years, $67 \%$ of pre-TDM were above 46 years, showing that diabetic recipients are older. The majority $(78 \%)$ of pre-TDM recipients were local nationals. Table 2 shows details of pretransplant dialysis and type of donors. Preemptive transplants were more common in ND (23\%) compared to pre-TDM (11\%) recipients. Even though live related donors were more frequent in ND recipients and live unrelated donors in pre-TDM, the differences were not significant. Live unrelated donors in 
Table 2. Pretransplant dialysis and type of donor

Table 3. Immunosuppression used in patients with pre-TDM and ND recipients

\begin{tabular}{|c|c|c|c|c|}
\hline & \multicolumn{2}{|c|}{ Pre-TDM } & \multicolumn{2}{|l|}{ ND } \\
\hline & $\mathrm{n}$ & $\%$ & $\mathrm{n}$ & $\%$ \\
\hline Preemptive & 9 & 11.4 & 101 & 23.2 \\
\hline \multicolumn{5}{|l|}{ Dialysis } \\
\hline Hemodialysis & 56 & 70.9 & 308 & 70.8 \\
\hline Peritoneal dialysis & 14 & 17.7 & 26 & 6.0 \\
\hline \multicolumn{5}{|l|}{ Donor } \\
\hline Live related & 25 & 31.6 & 202 & 45.9 \\
\hline Live unrelated & 48 & 58.2 & 202 & 45.9 \\
\hline Cadaver & 8 & 10.2 & 36 & 8.2 \\
\hline
\end{tabular}

\begin{tabular}{|c|c|c|c|c|c|}
\hline \multirow[t]{2}{*}{ Drugs } & \multicolumn{2}{|c|}{ Pre-TDM } & \multicolumn{2}{|l|}{ ND } & \multirow[t]{2}{*}{$\mathrm{p}$} \\
\hline & $\mathrm{n}$ & $\%$ & $\mathrm{n}$ & $\%$ & \\
\hline Pred + CyA & 5 & 6.3 & 17 & 3.9 & \\
\hline Pred + CyA + azathioprine & 69 & 87.3 & 328 & 75.8 & \\
\hline \multirow[t]{2}{*}{ Pred + CyA + mycophenolate } & 1 & 1.3 & 14 & 3.2 & \\
\hline & 75 & 94.9 & 359 & 82.9 & NS \\
\hline Pred alone & & & 1 & 0.2 & \\
\hline \multirow[t]{2}{*}{ Pred + azathioprine } & 4 & 5.1 & 73 & 16.9 & \\
\hline & 4 & 5.1 & 74 & 17.1 & NS \\
\hline
\end{tabular}

NS = Not significant Pred $=$ prednisone CyA = cyclosporin A.
Table 4. Post-transplant major nonimmunologic complications

\begin{tabular}{lcc}
\hline Complications & Pre-TDM & ND \\
\hline Infection (episodes requiring hospitalization) & \\
$\quad 113$ & 391 \\
$\quad$ Bacterial & 21 & 24 \\
$\quad$ Fungal & 7 & 9 \\
$\quad$ Mycobacterial & 9 & 33 \\
$\quad$ Viral & 1.9 & 1.0 \\
Infections per patient & 28 & 26 \\
Coronary heart disease & 3 & 3 \\
Cerebrovascular stroke & 5 & - \\
Peripheral vascular disease & 29 & 25 \\
Hyperlipidemia & 7 & 8 \\
Malignancy & 2 & - \\
Blindness & & \\
\hline
\end{tabular}

Diabetes mellitus in Renal Transplant
pre-TDM and ND groups were spouses (14 and 48), friends (14 and 68) and other emotionally related persons (20 and 86), respectively. Immunosuppression used in these recipients is shown in table 3 . There is no difference in the percentage of subjects receiving cyclosporin A including other immunosuppressants between pre-TDM and ND groups.

Major nonimmunological post-transplant complications are shown in table 4 . Incidence of significant infections requiring hospitalization was higher in recipients with pre-TDM than in ND throughout the period of follow-up. The localization of the infections in pre-TDM and ND recipients were septicemia (38 and 110), pneumonia (31 and 112), urinary tract (39 and 132), cutaneous abscess (13 and 10), gastrointestinal (4 each), hepatitis (2 and 3), meningitis (1 and 2), wound infection (9 and 42) and others (13 and 42), respectively. Similarly cerebrovas-

Med Principles Pract 2002;11:29-34 
Table 5. Causes of death

\begin{tabular}{|c|c|c|c|c|c|}
\hline \multirow[t]{2}{*}{ Cause } & \multicolumn{2}{|c|}{ Pre-TDM } & \multicolumn{2}{|l|}{ ND } & \multirow[t]{2}{*}{$\mathrm{p}$} \\
\hline & $\mathrm{n}$ & $\%$ & $\mathrm{n}$ & $\%$ & \\
\hline Infections & 14 & 56 & 20 & 48.9 & NS \\
\hline Coronary heart disease & 9 & 36 & 11 & 26.8 & $<0.001$ \\
\hline Cerebrovascular stroke & 1 & 4 & 4 & 9.8 & NS \\
\hline Malignancy & - & - & 3 & 7.3 & - \\
\hline Liver-related & - & - & 1 & 2.4 & - \\
\hline \multirow[t]{2}{*}{ Surgery-related } & 1 & 4 & 2 & 4.9 & NS \\
\hline & $25 / 79$ & 31.6 & $41 / 435$ & 9.4 & $<0.001$ \\
\hline
\end{tabular}

NS $=$ Not significant

Table 6. Causes of graft loss in patients with pre-TDM and ND

\begin{tabular}{lcccccc}
\hline \multirow{2}{*}{ Cause } & \multicolumn{2}{l}{ Pre-TDM } & & \multicolumn{2}{l}{ ND } & \multirow{2}{*}{$\mathrm{p}$} \\
\cline { 2 - 3 } & $\mathrm{n}$ & $\%$ & & $\mathrm{n}$ & $\%$ & \\
\hline Accelerated rejection & - & - & & 2 & 3 & \\
Acute rejection & 5 & 17.2 & & 11 & 16.4 & $\mathrm{NS}$ \\
Chronic rejection & 7 & 24.1 & & 32 & 47.8 & $\mathrm{NS}$ \\
Recurrent renal disease & - & - & & 2 & 3 & NS \\
Surgical causes & 1 & 3.4 & & 4 & 6 & NS \\
Died with functioning graft & 16 & 55.2 & & 16 & 23.9 & $<0.001$ \\
\hline & $29 / 79$ & 36.7 & & $67 / 440$ & 15.2 & $<0.05$ \\
\hline
\end{tabular}

NS = Not significant cular accidents (stroke) and coronary heart disease were observed more significantly more often in pre-TDM recipients. Peripheral vascular disease requiring amputation occurred only in recipients with pre-TDM. We also observed a higher prevalence of malignancies in the preTDM recipients. Three subjects developed recurrence of diabetic nephropathy in renal allografts.

Causes of death in 25 recipients with pre-TDM and 41 ND are shown in table 5. Patient mortality was significantly higher in pre-TDM $(\mathrm{p}<0.001)$. Even though infections formed a major cause of mortality in both groups, death due to coronary artery disease was significantly higher among pre-TDM recipients $(\mathrm{p}<0.001)$. During the follow-up period 29 grafts were lost in pre-TDM and 67 in the ND groups $(p<0.05$, table 6$)$. Death with functioning graft formed the major and significant cause of graft loss in the pre-TDM group $(p=0.001)$. Table 7 shows cumulative patient and graft survival in both groups. Recipients in the pre-TDM group had significantly lower survival
Table 7. Cumulative patient and graft survival (\%)

\begin{tabular}{llll}
\hline Year & Pre-TDM & ND & $\mathrm{p}$ \\
\hline Patient survival & & & \\
1 & 84 & 97 & $<0.01$ \\
5 & 65 & 93 & $<0.0001$ \\
10 & 58 & 86 & $<0.0001$ \\
14 & 58 & 82 & $<0.0001$ \\
\hline Graft survival & & & \\
1 & 85 & 95 & $<0.05$ \\
5 & 65 & 88 & $<0.0001$ \\
10 & 52 & 73 & $<0.0001$ \\
14 & 52 & 61 & $<0.01$ \\
\hline Censored graft survival & & \\
1 & 93 & 97 & NS \\
5 & 85 & 91 & NS \\
10 & 76 & 76 & NS \\
14 & 76 & 72 & NS \\
\hline
\end{tabular}

NS = Not significant 
showing the increased risk of mortality in pre-TDM compared to ND recipients.

The cumulative graft survival was significantly less in recipients with pre-TDM compared to ND (table 7). But censored graft survivals were not different between these groups (table 7). This showed the impact of dying with functioning graft in graft survival in recipients with preTDM.

\section{Discussion}

Over the past few years, there has been a growing tendency to perform kidney transplants on diabetic patients, thereby providing renal care personnel more information and experience in taking care of these patients [9]. Vascular disease is probably the major contributing factor to patient morbidity and mortality following transplantation in diabetic recipients $[10,11]$. In a 5-year survival of diabetic renal allograft recipients, diabetic patients without vascular disease (79\%) had a significantly higher survival rate than those with vascular disease (8\%) [13]. Other major factors associated with a higher incidence of cardiac death are hyperlipidemia, hypertension and extrarenal microangiopathy. Significant coronary artery disease, peripheral vascular disease and stroke could have definitely contributed to higher mortality in our diabetic recipients. Previous studies mainly concentrated on progression of vascular disease as a cause of higher mortality in diabetic recipients. Our findings are consistent with these reports. In addition, our data also indicate that infection is a contributing factor, although it also occurred at a similar rate in ND recipients.

There are varying reports on long- and short-term survival rates of diabetic recipients compared to those of ND [7, 10, 12-14]. While Eckberg and Christensson [7] and Shaffer et al. [13] reported similar rates, in the present study, pre-TDM had lower survival rates than ND. The probable explanation is that many elderly patients with occult diabetic vascular complications were included in the pre-TDM group. We recommend reduction of cardiovascular risk factors and subsequent better cardiovascular management as measures to improve patient survival in uremic diabetic patients. Recently, calcium channel blockers have been shown to improve both patient and graft survival in diabetic recipients [15].

Death of patients with functioning graft was the major cause of graft loss in pre-TDM recipients in this study. Similar observations were made earlier where two thirds of graft loss were due to patient death [13]. Other causes of graft loss were similar in pre-TDM and ND recipients throughout the period of follow-up. Hence it can be presumed that pre-TDM or its milieu has no direct impact on the graft itself.

\section{Conclusion}

Recipients with pre-TDM have increased mortality mainly due to cardiovascular complications. This is also accompanied by inferior patient and graft survival after transplantation compared with ND. Patients dying with functioning graft continue to be the reason for inferior graft survival in pre-TDM recipients. We recommend screening of diabetics with end-stage renal disease carefully for vascular disease and avoiding transplantation in those who are found to have advanced disease for improving survival in diabetic patients with end-stage renal disease. Even with this type of screening, transplantation and follow-up in diabetic uremics will still remain a challenge.

\section{Acknowledgment}

We wish to express our sincere gratitude and thanks to $\mathrm{Mr}$. George Varughese for secretarial assistance and Dr. Mini Abraham Puliyelil for technical assistance in the preparation of the manuscript. 


\section{References}

1 Tzamaloukas AH: Renal failure in diabetics; in Daugirdas JT, Ing S: Handbook of Dialysis. Boston, Little Brown, 1994, pp 110-115.

2 Comty CM, Kjellsen D, Shapiro FL: A reassessment of the prognosis of diabetic patients treated by chronic haemodialysis. Trans Am Soc Artif Intern Organs 1976;22:404-410.

3 Najarian JS, Sutherland DE, Simmons RL, Howard RJ, Kjellstrand CM, Ramsay RC, Goetz FC, Fryd DS, Sommer BG: Ten years experience with renal transplantation in juvenile onset diabetics. Ann Surg 1979;190:487500.

4 Parfrey PS, Hutchinson TA, Harvey C, Guttmann RD: Transplantation versus dialysis in diabetic patients with renal failure. Am J Kidney Dis 1985;5:112-116.

5 Rao KV, Sutherland DE, Kjellstrand CM, Najarian JS, Shapiro FL: Comparative results between dialysis and transplantation in diabetic patients. Trans Am Soc Artif Intern Organs 1977;23:427-432.
6 Jacobs C, Brunner FP, Brynger H: The first five thousand diabetics treated by dialysis and transplantation in Europe. Diabet Nephropathy 1983;2:12-16.

7 Ekberg H, Christensson A: Similar treatment success rate after renal transplantation in diabetic and non diabetic patients due to improved short and long term diabetic patient survival. Transpl Int 1996;9:557-564.

8 Munson JL, Bennett WM, Barry JM, Norman DJ: A case control study of renal transplantation in patients with type 1 diabetes. Clin Transplant 1992;6:306-311.

9 Gonzalez ZA: Improved results of kidney transplantation in diabetic patients. Transplant Proc 1994;26:312-315.

10 Kumar S, Merchant MR, Dyer P, Martin S, Hutchinson AJ, Johnson RW, Boulton AJ, Gokal R: Increased mortality due to cardiovascular disease in type 1 diabetic patients transplanted for endstage renal failure. Diabet Med 1994; 11:987-991.

11 Hirschl MM, Heinz G, Sunder-Plassmann G, Derfler K: Renal replacement therapy in type 2 diabetic patients: 10 years experience. Am J Kidney Dis 1992;20:564-568.
12 Rischen-Vos J, van der Woude FJ, Tegzess AM, Zwinderman AH, Gooszen HC, van der Akker PJ, van Es LA: Increased morbidity and mortality in patients with diabetes mellitus after kidney transplantation as compared with nondiabetic patients. Nephrol Dial Transplant 1992;7:433-437.

13 Shaffer D, Simpson MA, Madras PN, Sahyoun AI, Conway PA, Davis CP, Monaco AP: Kidney transplantation in diabetic patients using cyclosporine. Arch Surg 1995;130:283-288.

14 Sutherland DE, Morrow CE, Fryd DS, Ferguson R, Simmons RL, Najarian JS: Improved patient and primary renal allograft survival in uraemic diabetic recipients. Transplantation 1982;34:319-325.

15 Weinrauch LA, D'Elia JA, Gleason RE, Shaffer D, Monaco AP: Role of calcium channel blockers in diabetic renal transplant patients: Preliminary observations on protection from sepsis. Clin Nephrol 1995;44:185-192. 